\title{
Sub-basins prioritization using morphometric analysis-remote sensing technique and GIS-Golestan-Iran
}

\author{
Mohamad Amani ${ }^{1}$, Arezoo Safaviyan ${ }^{2}$ \\ ${ }^{1} \mathrm{MSc}$ Watershed, Agricultural and Natural Resources University of Gorgan, Iran \\ ${ }^{2} \mathrm{MSc}$ Agricultural and Natural Resources University of Gorgan, Iran \\ *E-mail address: amani.watershed@gmail.com \\ Safavian_az@yahoo.com
}

Keywords: prioritization; morphometric; SYI; erodibility; Lohender basin

\begin{abstract}
Sub-basins prioritization is one of the most important resolutions of development sustainability and natural resources comprehended management. In this study, 11 sub-basins of Lohender in east Golstan province about $272 / 63 \mathrm{~cm}$ Prioritized using computation and morphometric analysis and using GIS and RS techniques. Erosion mode in each sub-basin specified through Sediment Yield Index approximation. In morphometric analysis, parameters like canal length, bifurcation ratio, discharge density, sub-basins shape coefficient, round coefficient, stretch coefficient and compressive coefficients were computed thus these parameters divided to two classifications: linear coefficients and figurative coefficient. In order to study annual sediment index, from fields applied maps, land coverage, slope, soil type and topographic map scale 1:50000 were used. Finally, each sub-basin Priority determined due to Sediment Yield Index (SYI) and total average of morphometric parameters. According to morphometric parameters, the BS sub-basin and according to SYI parameter, A5 sub-basin showed more critical mode and combination of both showed that B2 sub-basin showed the worst situation.
\end{abstract}

\section{INTRODUCTION}

Basin is an ideal unit for natural resources management; also harmonize natural disaster consequences in order to achieve sustainable development.6. First requirement of corrosive factors control and critical mode improvement in a basin is to identify most critical basins and sub-basins and Sub-basins prioritization, so that in control operation execution case, high priority regions addressed more and protective programs focused on these areas. Sub-basins prioritization includes sub-basins ranks based on current resources, requirement and mode and erosions severity. Finally result in protective program and watershed in sensitive sub-basins with high priorities.13. Great basin divisions to various sub-basins, study and Prioritize sub basins save time and costs of watershed execution operation and promote higher efficacy of these plans. Prioritize based on main factors of design and development of a catchment basin like physiography features, drainage network, geomorphology, soil, land use, land coverage, and water resources of the region was performed.

Lohender catchment basin in mountain area of east Golstan province located at Shelmi mountain range which is one of the eastern sub-basins of Gorgan River. Studied watershed witness various kind of erosion indicate high or low various factors influence besides human factor influences.8. Due to clay soils in the area, soil role is more significant than geology factors on production and erosion severity.8. Studied area's soils in fabric point are clay loam silt, clay loam, loam silt and loam types totally silt rate is higher than sand and clay and they show high sensitivity to erosion.8. Due to various kinds of erosions in the area, Sub-basins prioritizations are vital and inevitable in order to watershed operation. Plenty of literature published about watershed Subbasins prioritization. In brief, they will be explained as follow: khan et.al (5), Prioritize Guhiya basin of India based on erodibility and SYI also using current techniques like RS and GIS. Martin\& Saha (8). By combination of GIS and remote sensing Sub-basins prioritization and outputted soils erosion rate using output USLE model. Takar and Diman (14) using morphometric analysis and 
remote sensing and GIS Prioritize 8 sub basin watershed in Mohr India. Javood and Khandai (4), Prioritize Kanera catchment sub-basins of india based on morphometric features and land use of the area. Kumarjan and dus (9), Prioritize Haharo catchment sub-basins of India by computing SYI value, erosion rate, and sediment using RS and GIS. Jamali et,al (3), Sub-basins prioritization based on hierarchical analysis in order to set up stone net dams and based on their study results, errodiblility and impenetrate levels are the main factors of critical mode of sub-basins. Picock et al (12). Sub-basins prioritization carried out in order to non-spot pollution resource, management in four economic, social, environmental, and cultural dimensions. In above mentioned literature, catchment Sub-basins prioritization is often one dimensional and carried out for the area water supply. And land use and land plant coverage are the main factors in area mode determination and Prioritize carried out based on these parameters tendency and deconstructive.. This research aims to determine critical mode sub-basins in order to control all kinds of erosions in the area also to accelerate and decrease expenses in control and watershed projects.

\section{MATERIALS AND METHODS}

Lohender catchment located in east of Golestan province about 50km northeast of Kelaleh County. This is one of the eastern sub-basins of Gorgan river great basin. In fact, it's located at 55, $5000 \mathrm{E}$ and $56,0600 \mathrm{E}$ longitude and $37,2500 \mathrm{~N}$ and $37.3700 \mathrm{~N}$ latitude and the main villager is Lohender. This is semi round basin and average slope is $16.3 \%$ height from sea level is $1343 \mathrm{~m}$. this basin includes 11 sub-basins. Sub-basin position and total form of it showed in figure1. (8). In this research, first, morphometric measures and SYI value of each Lohender catchment sub-basins calculated and by comparing results obtained from both these indices, sub-basins were Prioritized for watershed operation and erosion rate. SYI index is the most important criteria to compute and determine erosion value and severity in a region also has positive and direct relationship with erosion factors (area, erosive processes, sediments and SDR value)(3). Indices computation levels and achieving final map of priority in each sub-basin showed at figure2:

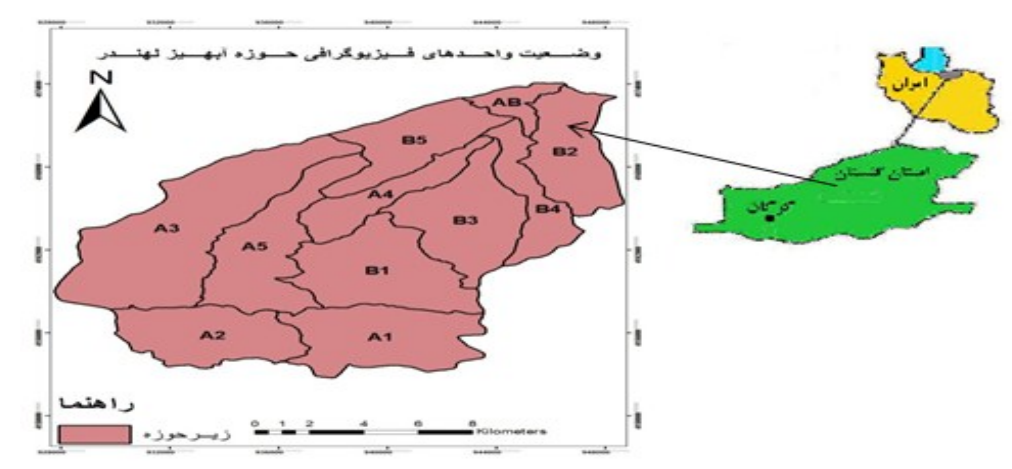

Figure1. Base map and condition of Lohender basin physiography units. 


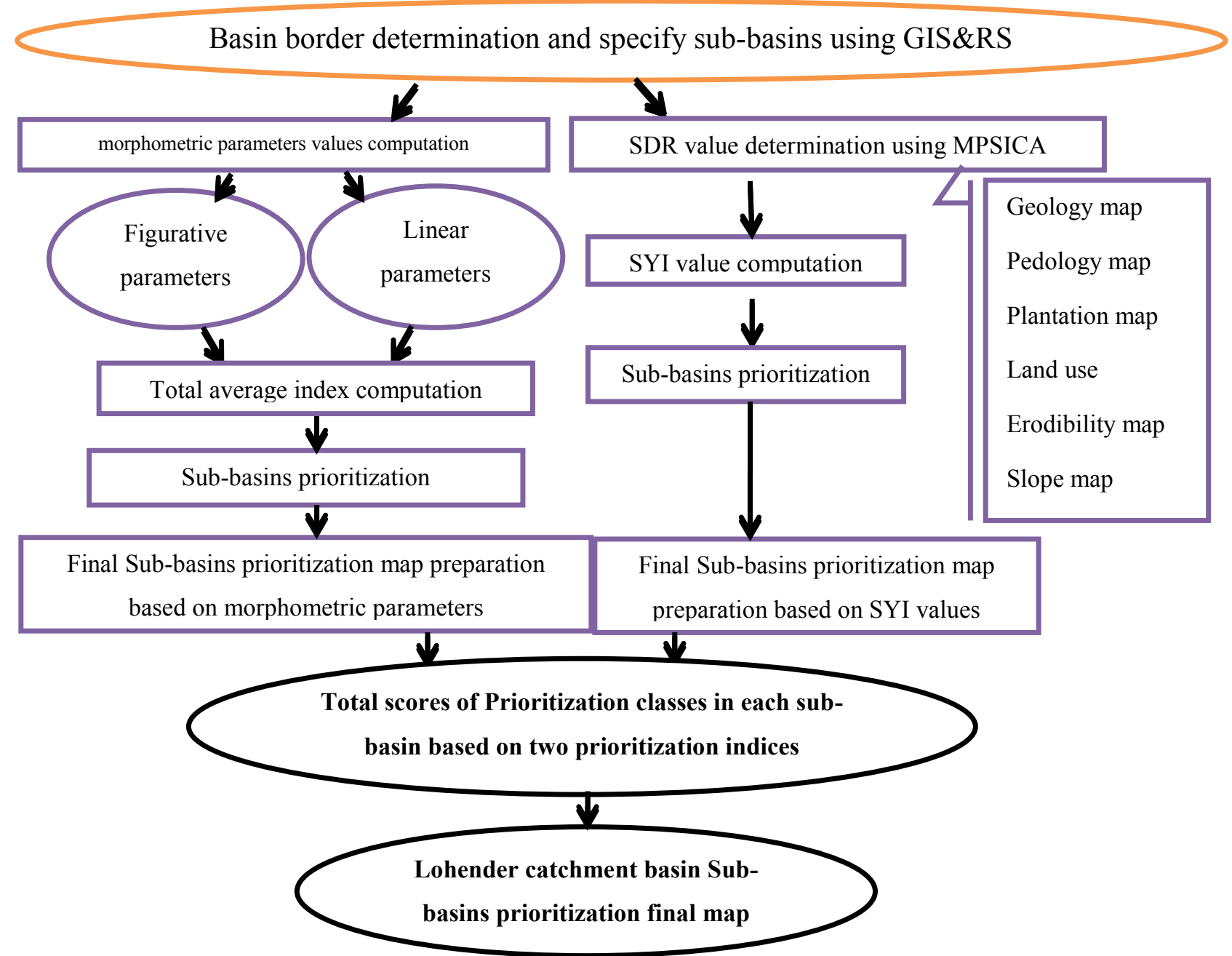

Figure2. Sub-basins Priority final map preparation trend diagram

\section{2-1- Morphometric specifications}

Morphometric analysis is one of the effective methods for Sub-basins prioritization might indicate the catchment drainage network mode (5). Also, this factor is one of the important tools of Sub-basins prioritization without soil map survey in the area (8). basin shape indicate flooding and concentrate time and drainage pattern indicate geology mode and region soil type. Thus, morphometric parameters study indicates basin mode and appropriate rate of requirement for erosion and erosion rate in the area (8). These features include more parameters that in current research most influential parameters in Priority and erosion mode were selected and their values determined. Morphometric parameters divide to liner and figurative parameters (5).

- Linear parameters: that shows direct and positive relationship with erosion and lowest rank devoted to highest value of these parameters and highest rank devoted to lowest value of these parameters. This group includes: drainage density, bifurcation ratio, and stream length. And form factor.

- Figurative parameters: shows negative relationship with erosion and instead of linear parameters highest rank belongs to highest value and lowest rank to lowest value. This category includes: elongation ratio, compactness coefficient, circulatory ratio, and form factor. By computing average given ranks to each category of morphometric parameters in each sub-basin it might place sub-basins to seven categories due to table1: 
Table1. Morphometric parameters class determination due to related average.

\begin{tabular}{|c|c|c|}
\hline Average & Signs & Priority \\
\hline Critical & A & $<2.4$ \\
\hline Very High to critical & B & $2.5-3.5$ \\
\hline High to very high & C & $3.6-4.6$ \\
\hline Medium to high & D & $4.7-5.7$ \\
\hline Low to medium & E & $5.8-6.8$ \\
\hline Very low to low & F & $6.9-7.9$ \\
\hline Lowest & G & $>8$ \\
\hline
\end{tabular}

\section{2-2- Sediment yield index (SYI)}

It was introduced by Carl and Bali at 1977 and might reflect two main parameters of erodible and sediment delivery ratio (index for value determination of sediment transported to dam reservoir or basin exit), in each basin (6). Using geography information system (GIS) is the most effective method for identification and computation of sediment production resources and sensitive area to erosive factors and also determination of sediment yield index value (SYI) in catchment basins (7).

Wastage soil value approximation and identification of critical areas are main factors playing important role in appropriate managerial operation in order to keep preserve soil and water resources in catchment basins (11). Influential factors in the index computation are as follow: land use and plant coverage, soil (high potential in erosion studies), and slope (an important map for ground studies). Sediment yield index value (SYI) computation is the influential factor playing significant role in catchment basin studies and development used without precipitation data for Subbasins prioritization. Sediment yield index value (SYI) equation consists of two input parameters as erosion and delivery ratio as follow (6):

$$
\text { Equation 1: } \quad S Y I=E \times S D R \times 100 \quad E=\frac{\Sigma(A e i \times W e i)}{A w}
$$

Where, $\mathbf{E}$ is basin erodibility, Wei is special weight to erosion ratio in each sub-basin, Aei: sub-basins area, Aw: total catchment basins area, SDR: sediment delivery ratio. Obtained SYI values interpretation for each basin might determine all basins priority. SYI high values indicate higher priority and critical mode of the area (9). This index might be classified in 7 categories as table2 shows:

Table2: SYI values priority and class determination

\begin{tabular}{|c|c|c|}
\hline SIGN & Priority & SYI \\
\hline G & Lowest & $<5$ \\
\hline F & Low & $5-10$ \\
\hline E & Very low & $10-15$ \\
\hline D & Medium & $15-20$ \\
\hline C & High & $20-25$ \\
\hline B & Very high & $25-30$ \\
\hline A & Critical & $>30$ \\
\hline
\end{tabular}

\section{2-3- Morphometric specifications computation}

In Sub-basins prioritization, Morphometric analysis includes figurative and linear parameters. Area basic maps created using current references of Golestan province natural resources 
department. Area drainage network prepared using ARC/INFO software and each canal rank extracted using Strahler formula. Lohender basin drainage area map prepared in order to compute stream elongation in all sub-basins due to area DEM map and using ARC Hydro in GIS environment. (figure3).stream length showed negative relationship to canal slope, so that the highest stream length related to (16.95) A3 sub-basin and the least one is $3 / 08 \mathrm{~km}$ in AB sub-basin. Then, due to weights related to each parameter, total average weights of each sub-basin computed according to equation2.

\section{Equation2.}

Total Average $=\{($ total weights of figurative parameters $)+($ total linear parameters weights $)\} /$ Total parameters number

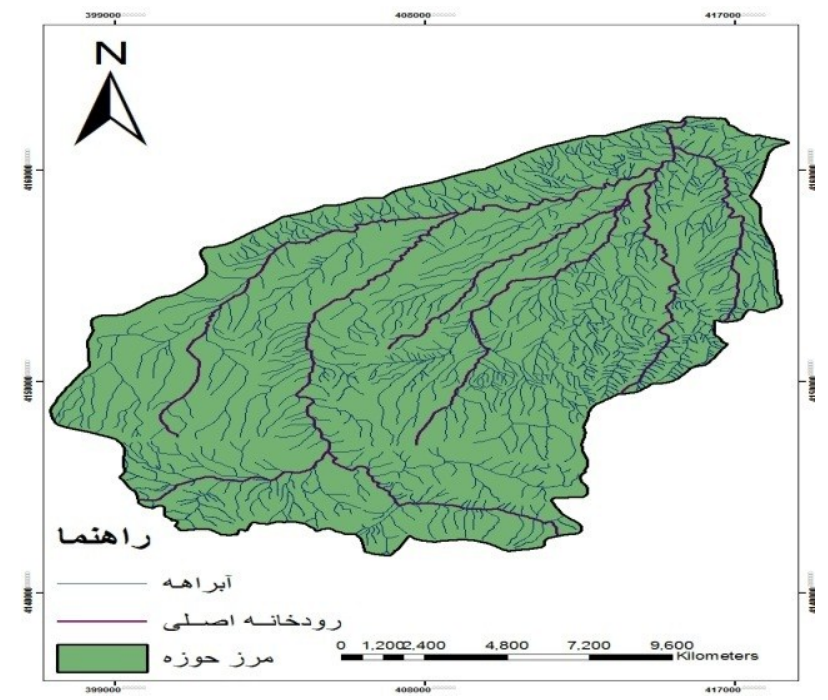

Figure3. Lohender area drainage and canal network

\section{2-4- Sediment yield index value (SYI) computation}

In order to compute sediment yield index value (SYI), it was required land use layers, earth plant coverage, slope and Pedology to characterize sensitivity and erosion severity those prepared using remote sensing data in Arc GIS environment. Pedology and land use maps prepared by Golestan province natural resources department (1) and slope map (figure5) prepared with area interval height figurative map. Based on equation1, influential factors for SYI value computation includes all sub-basins area, and sea-ward dipping reflection or SDR, thus by computing each of these factors and putting them in equation, the final sediment yield index value (SYI) of all subbasins were computed (table5). At last, final obtained values for both used indices (Morphometric analysis and sediment yield index value (SYI) ranked. The lowest rank devoted to the highest Morphometric index value, instead, highest rank devoted to highest sediment yield index value (SYI) value. Sum up obtained ranks; Sub-basins prioritization determined, thus, the higher final weight value indicate higher priorities. (table6).

\section{RESULTS AND DISCUSSION}

Total average computed values of Morphometric parameters in each sub-basin (table3) inserted in specified classes due to table1. (table4) .the lower Morphometric parameters total averages indicate more critical area mode and more appropriate erodibility of area. Figure 4 shows each Sub-basin prioritization based on Morphometric analysis and according to table 4 . 
Table3. Morphometric parameters values and related weight determination

\begin{tabular}{|c|c|c|c|c|c|c|c|c|}
\hline \multicolumn{4}{|c|}{ Figurative parameters } & \multicolumn{3}{|c|}{ linear parameters } & \multirow[b]{2}{*}{ Area(km2) } & \multirow[b]{2}{*}{ sub-basin } \\
\hline $\begin{array}{c}\text { Shape } \\
\text { coefficient }\end{array}$ & $\begin{array}{c}\text { Circulatory } \\
\text { ratio }\end{array}$ & $\begin{array}{c}\text { compactness } \\
\text { coefficient }\end{array}$ & $\begin{array}{c}\text { Elongation } \\
\text { ratio }\end{array}$ & Stream length & Bifurcation ratio & $\begin{array}{c}\text { drainage } \\
\text { density }\end{array}$ & & \\
\hline $0 / 42(9)$ & $0 / 51(10)$ & $1 / 43(3)$ & $0 / 73(9)$ & $9 / 5(6)$ & $4 / 47(6)$ & $2 / 7(10)^{*}$ & $28 / 6$ & A1 \\
\hline $0 / 63(11)$ & $0 / 61(11)$ & $1 / 28(1)$ & $0 / 89(11)$ & $6 / 86(10)$ & $3 / 98(9)$ & $2 / 91(8)$ & 24 & A2 \\
\hline $0 / 23(4)$ & $0 / 44(7)$ & $1 / 52(5)$ & $0 / 56(5)$ & $16 / 95(1)$ & $4 / 64(5)$ & $2 / 55(11)$ & $55 / 2$ & $\mathrm{~A} 3$ \\
\hline $0 / 20(3)$ & $0 / 28(2)$ & $1 / 90(10)$ & $0 / 49(3)$ & $14 / 8(2)$ & $5 / 77(3)$ & $2 / 8(9)$ & $29 / 06$ & A4 \\
\hline $0 / 26(6)$ & $0 / 42(5)$ & $1 / 54(7)$ & $0 / 58(6)$ & $7 / 87(7)$ & $3 / 47(11)$ & $3 / 47(5)$ & $21 / 15$ & A5 \\
\hline $0 / 48(10)$ & $0 / 50(9)$ & $1 / 41(2)$ & $0 / 78(10)$ & 7/71 (9) & $4 / 37(7)$ & $3 / 18(7)$ & $30 / 95$ & B1 \\
\hline $0 / 14(2)$ & $0 / 31(3)$ & $1 / 79(9)$ & $0 / 42(2)$ & $11 / 07(4)$ & $6 / 13(2)$ & $3 / 4(6)$ & $13 / 78$ & $\mathrm{~B} 2$ \\
\hline $0 / 32(7)$ & $0 / 45(8)$ & $1 / 51(4)$ & $0 / 63(9)$ & $10 / 32(5)$ & $4 / 92(4)$ & $3 / 85(4)$ & $22 / 13$ & B3 \\
\hline $0 / 24(5)$ & $0 / 43(6)$ & $1 / 53(5)$ & $0 / 55(4)$ & $7 / 73(8)$ & $6 / 63(10)$ & $4 / 38(1)$ & $27 / 92$ & B4 \\
\hline $0 / 13(1)$ & $0 / 25(1)$ & $2 / 02(3)$ & $0 / 40(1)$ & $13 / 48(3)$ & $4 / 2(8)$ & $4 / 35(2)$ & $14 / 31$ & B5 \\
\hline $0 / 38(8)$ & $0 / 34(4)$ & $1 / 70(8)$ & $0 / 70(8)$ & $3 / 08(11)$ & $10 / 5(1)$ & $4 / 28(3)$ & $5 / 53$ & $\mathrm{AB}$ \\
\hline
\end{tabular}

*parentheses indicate parameters weights.

Table4. Priority class determination in all sub-basins based on Morphometric analysis.

\begin{tabular}{|c|c|c|c|c|c|}
\hline Class & $\begin{array}{c}\text { Ranks } \\
\text { average }\end{array}$ & sub-basins & Class & $\begin{array}{c}\text { Ranks } \\
\text { average }\end{array}$ & sub-basins \\
\hline C & 4 & B2 & F & 7.57 & A1 \\
\hline D & 5.57 & B3 & G & 8.71 & A2 \\
\hline E & 5.71 & B4 & D & 5.43 & A3 \\
\hline C & 3.86 & B5 & C & 4.57 & A4 \\
\hline E & 6.14 & AB & E & 6.71 & A5 \\
\hline$* * * *$ & $* * * *$ & $* * * *$ & F & 7.71 & B1 \\
\hline
\end{tabular}

\section{GUIDE:}

C: High

D: Medium to high

E: Medium to low

\section{F: Low to very low}

G: Very low

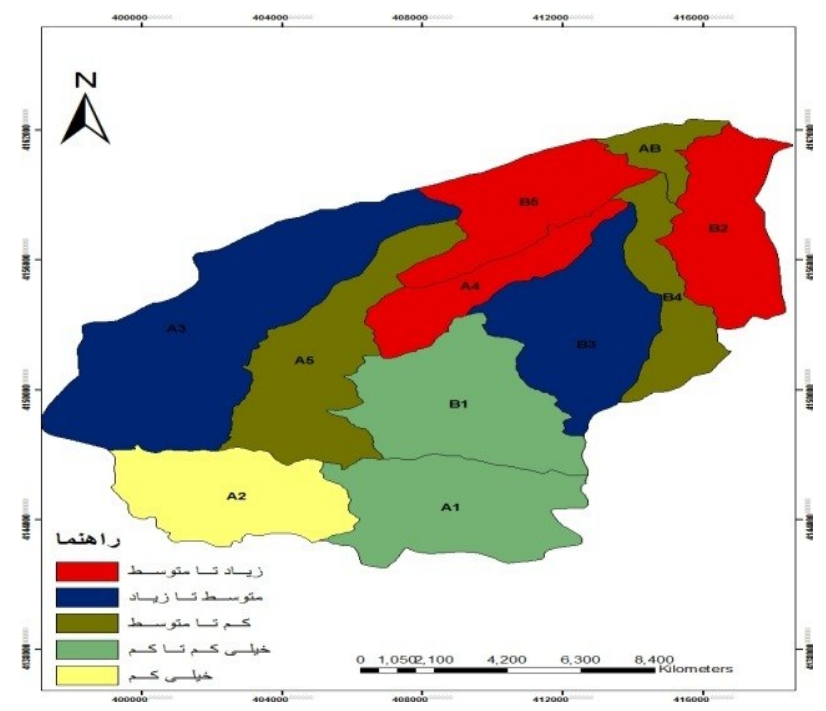

Figure4. Prioritize sub-basins based on Morphometric parameters. 
Slope point prepared through height figurative map intervals (figure5). Geological disconnected facades, cement lack among particles, and soil fine grains are the main influential factors of reverse stream, sediment and erosion production and in canals they results in edge erosion and higher sediment rate and soil grain and structures stability decrease. (1). Two important factors in computation of sediment yield index value (SYI), land and soil use indicate area erosion mode and severity (3). Basin soil hydrology groups are shown in figure6. This basin consists of 3 application types: natural jungle, pasture and fertilized fields, so that the highest rate belongs to pasture (58\%) (1). the area soil mostly is hydrology B type includes loam sandy, sand clay soils and partly potential for runoff production. Penetration rate of this group is 1.5 to 3 inches per hour (3).

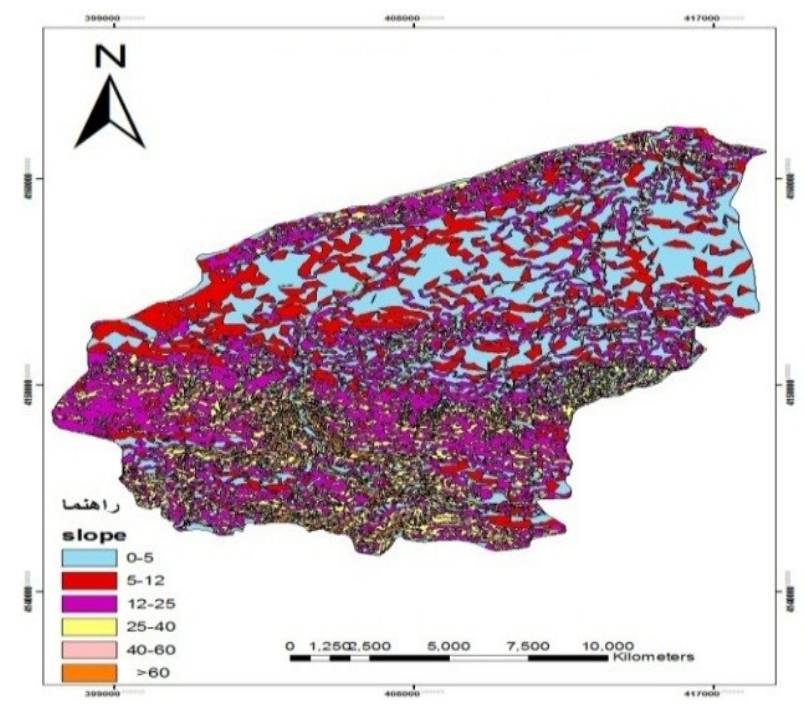

Figure5: Lohender basin slope values classification

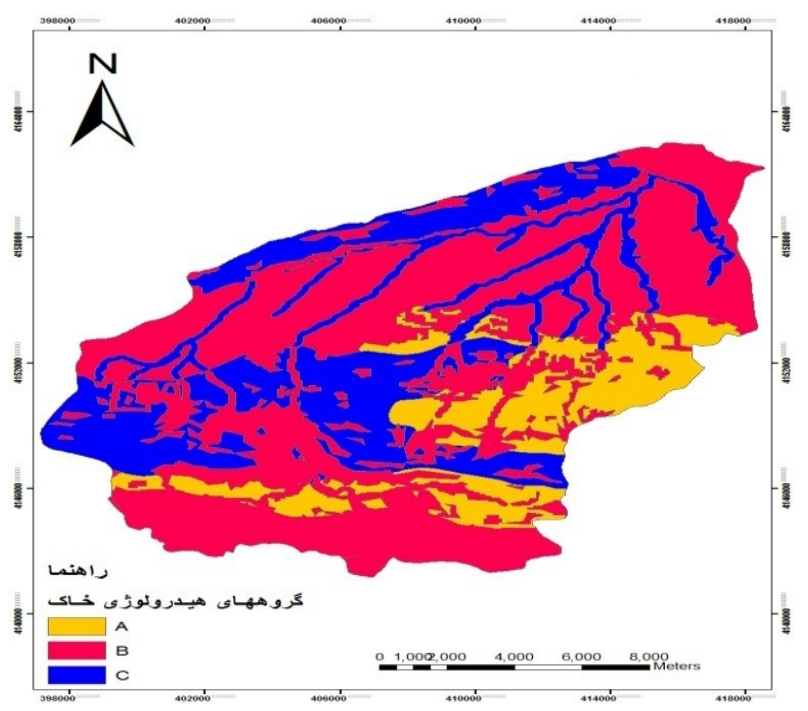

Fighure6-Lohender catchment basin soil hydrology groups.

In table5, factors intermediate in sediment yield index value (SYI) formula and final values of each sub-basin were computed, then they were prioritize sub-basins according to table2. 
Table5. Determination of sediment yield index value (SYI) value and prioritization in sub-basins

\begin{tabular}{|c|c|c|c|c|c|}
\hline sub-basin & Area $\mathbf{( k m}^{2} \mathbf{)}$ & SDR & WI & SYI & CLASS \\
\hline A1 & $28 / 6$ & $38 / 63$ & 4 & $16 / 21$ & D \\
\hline A2 & 24 & $39 / 60$ & 6 & $20 / 92$ & C \\
\hline A3 & $55 / 2$ & $35 / 18$ & 1 & $7 / 12$ & F \\
\hline A4 & $29 / 06$ & $38 / 54$ & 3 & $12 / 32$ & E \\
\hline A5 & $21 / 15$ & $40 / 32$ & 8 & $25 / 02$ & B \\
\hline B1 & $30 / 95$ & $38 / 19$ & 2 & $8 / 67$ & F \\
\hline B2 & $13 / 78$ & $42 / 84$ & 10 & $21 / 65$ & C \\
\hline B3 & $22 / 13$ & $40 / 06$ & 7 & $22 / 76$ & C \\
\hline B4 & $27 / 92$ & $38 / 76$ & 5 & $19 / 85$ & D \\
\hline B5 & $14 / 31$ & $42 / 61$ & 9 & $20 / 13$ & C \\
\hline AB & $5 / 53$ & $48 / 77$ & 11 & $10 / 88$ & E \\
\hline Total & $272 / 63$ & ---- & ---- & $185 / 54$ & --- \\
\hline
\end{tabular}

The higher sediment yield index value (SYI) the higher erosion rate and sediment production, in results higher priority and more critical sub-basins created. Figure7 shows Sub-basins prioritization final map based on sediment yield index value (SYI).

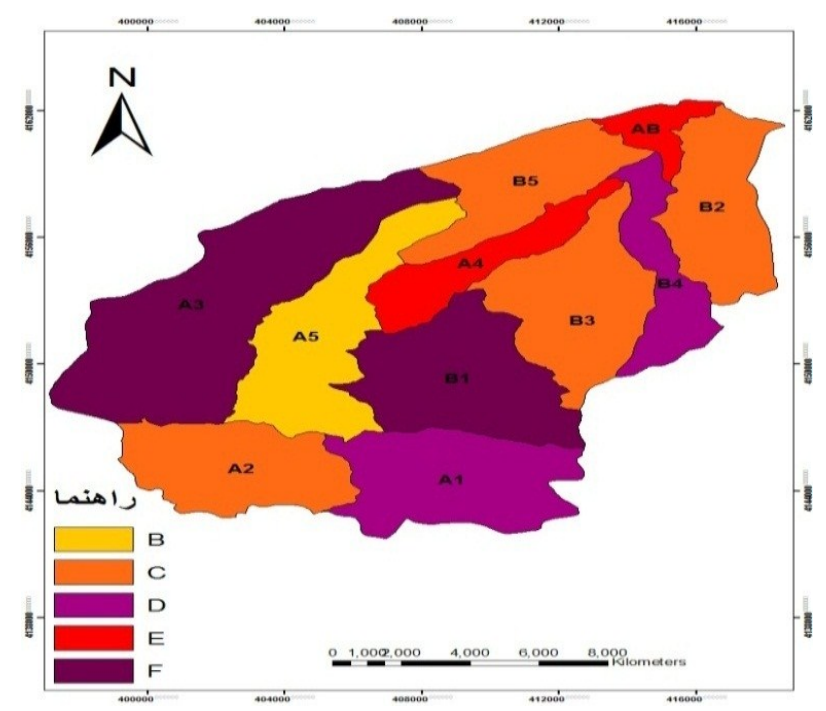

Figure7.Lohender sub-basins priority based on sediment yield index value (SYI)

Using table 6 as a combination of both indices of this research, final priority and critical requirement of sub-basins were determined. Finally, sub-basins priority map showed in figure8.

Table6. Total given weights to both indices and sub-basins final priority determination

\begin{tabular}{|c|c|c|c|c|c|c|}
\hline sub-basin & SYI & Rank & $\begin{array}{c}\text { morphometric } \\
\text { parameters }\end{array}$ & Rank & $\begin{array}{c}\text { Total } \\
\text { weight }\end{array}$ & $\begin{array}{c}\text { Final } \\
\text { priority }\end{array}$ \\
\hline A1 & $16 / 21$ & 5 & $7 / 57$ & 3 & 8 & $\boldsymbol{9}$ \\
\hline $\mathbf{A 2}$ & $20 / 92$ & 8 & $8 / 71$ & 1 & 9 & 7 \\
\hline $\mathbf{A 3}$ & $7 / 12$ & 1 & $5 / 43$ & 8 & 9 & $\boldsymbol{8}$ \\
\hline $\mathbf{A 4}$ & $12 / 32$ & 4 & $4 / 57$ & 9 & 13 & $\boldsymbol{5}$ \\
\hline $\mathbf{A 5}$ & $25 / 02$ & 11 & $6 / 71$ & 4 & 15 & $\mathbf{4}$ \\
\hline B1 & $8 / 67$ & 2 & $7 / 71$ & 2 & 4 & $\mathbf{1 1}$ \\
\hline B2 & $21 / 65$ & 9 & 4 & 10 & 19 & $\mathbf{1}$ \\
\hline B3 & $22 / 76$ & 10 & $5 / 57$ & 7 & 17 & $\boldsymbol{3}$ \\
\hline B4 & $19 / 85$ & 6 & $5 / 71$ & 6 & 12 & $\boldsymbol{6}$ \\
\hline B5 & $20 / 13$ & 7 & $3 / 86$ & 11 & 18 & $\boldsymbol{2}$ \\
\hline AB & $10 / 88$ & 3 & $6 / 14$ & 5 & 8 & $\mathbf{1 0}$ \\
\hline
\end{tabular}


As seen from table 6, sub-basins final weights (A2, A3) and also (AB, A1) are equal, so that prioritization priority to other sub-basins determined due to sediment yield index value (SYI). The higher values of this index indicate erodibility and sensitivity of area requirements. Therefore, A2 shows higher worse situation and priority than A3, and A1 shows worse situation higher priority than AB. Figure7 shows respective priorities in studied sub-basins classified in 11 categories, first category indicated highest priority and worst situation instead category 11 indicate least priority and best situation than other sub-basins.

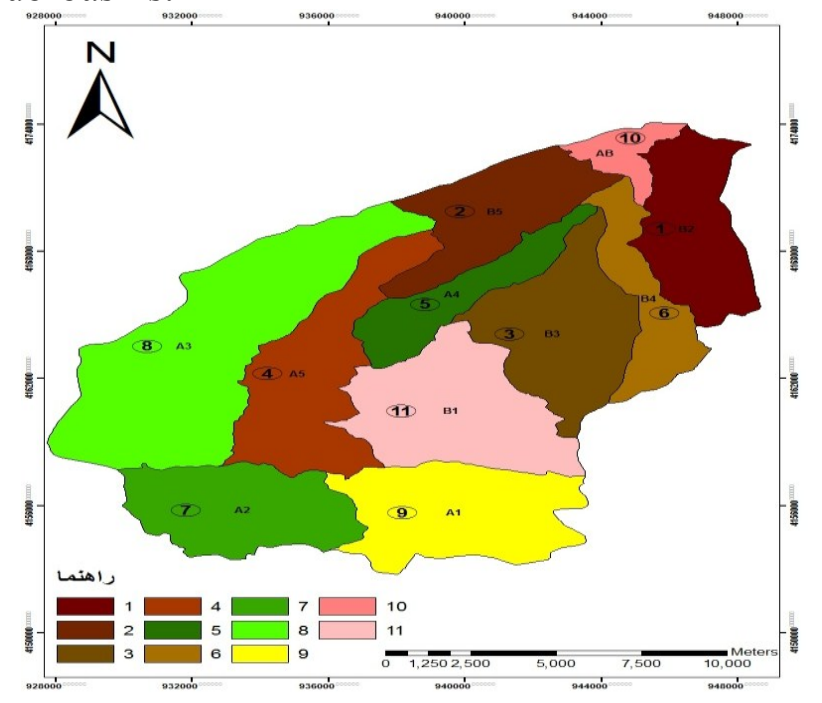

Figure8. Final and combination map of Lohender catchment sub-basins priority

This research aims to determine priorities all Lohender catchment sub-basins and identify critical areas for control and protective operations in this area. Geology s the main factor of erosion and destruction in an area so that in this case study due to Lessi sediment debris and Sarchaman and Sarcheshme constructions they shows high erosion-sensitivity. Thus; lowest sensitivity devoted to A2 sub-basin and highest sensitivity rate devoted to A3, A5 sub-basins. Combination of results obtained from Sediment Yield Index (SYI) and morphometric parameters is an efficient technique for prioritize sub-basins in order to carry out soil protection operation.13.alo, its important to mention that this study indicate remote sensing and GIS techniques potential and application to prioritize catchment-basin based on Sediment Yield Index (SYI) and morphometric parameters or combination of both. According to studies in Lohender catchment sub-basin and due to tables 3 and 4 in point of morphometric specification, (B5-B2-A4) sub-basin showed higher critical mode, amongst B5 sub-basin showed the highest priority due to shape coefficient parameter's least value (0.13), circular ratio (0.25), elongation ration (0.40) and lowest average value of total morphometric parameters than other sub-basins. This is confirmed by Takar et.al (14) studies about morphometric parameters influences on -basins erodibility. Now, due to results obtained from Sediment Yield Index (SYI) in tables2 and 5, (A5-B3-B2-A2) sub-basins ranked first priority to fourth respectably. Due to erosion-sensitive Lessi soils and planted farm and also human intervention, A5 sub-basin showed 40.32 ton SDR per acre and worse situation as confirmed by obtained results from Jaud aet.al (4) and Jamali et,al (3). Due to table6 results also final map priorities (figure8) as combination of both Sediment Yield Index (SYI) and morphometric parameters, all Lohender catchment subbasins priorities from 1 to 11 . According to the map, B2 sub-basin gained highest priority and worst erosion situation and require urgent protection and control operations. Second priority devoted to B5 sub-basin. Then it must indicate that in Lohender catchment basin must be focus on more critical sub-basin (B3-B5-B2) due to morphologic and topographic conditions of sub-basin also natural and human induced erosion factors in order to prevent soil and water resource wastage and severe consequences of high level erosions. In these areas, due to critical situation and climate and topographic conditions it's better to use mechanical and biological operation simultaneously. Due to topographic situation and basin's hydrology and ecology optimization, it's better to devote these 
areas to vast resort and entertaining application. The main significant point it must use domestic experts proposals and points of views and also local people experiences for protective operation in critical areas.

\section{References}

[1] Artin, D. and S.K, Saha. 2007. Integrated approach of using RS and GIS to study watershed prioritization and productivity. Journal of the Indian society of Remote Sensing Vol. 35, No. 1: $10 \mathrm{pp}$.

[2] Department of Natural Resources, Golestan Province, 1385. Detailed project executive Kalaji and Agh Ghala areas of the first and third volumes.

[3] Devante, J. and J, Poesen. 2005. Predicting soil erosion and sediment yield at the basin Scale issues and semi-quantitative models. Earth since Reviews 71:95-125.

[4] Jamali, A. J, Ghodusi, and M, Farah Bakhsh. 1390. Spatial multi criteria analysis techniques in order to watershed prioritizing for gabion check dams building. Journal Research and development. No 90. 10pp.

[5] Javed, A. and M.Y, Khanday. R, Ahmed. 2009. Prioritization of watersheds based on morphometric and landuse analysis using RS and GIS techniques. Journal of the Indian society of Remote Sensing 37: 261-274.

[6] Khan, M.A. V.P, Gupta. and P.C, Moharana. 2001. Watershed prioritization using RS and GIS: a case study from Guhiya, India. Journal of Arid Environments 49: 456-475.

[7] Kashy, L. 1390. Watershed priority mapping using GIS-based multivariate regression model (MR) in the watershed Zenouz city. Seventh National Conference on Watershed Management Science and Engineering. 7pp.

[8] Kumar jain, M. D, Debjyoti. 2010. Estimation of SYI and areas of Soil erosion and deposition for watershed prioritization using GIS and RS. Water Resource Manage 24. 2091-2112.

[9] Mahdavi, M. 2001. Applied Hydrology. $2^{\text {nd }}$ Vol . Tehran University press. 438pp.

[10] Pandey, A. V.M, Chawdary. B.C, Mal. 2007. Identification of critical erosion prone areas in the small agricultural watershed using USLE, GIS and RS. Water Resource Manage 21.729-746.

[11] Peacock, V. D, Hikuroa. Morgan, T.K.K.B., 2012. Watershed-scale prioritization of habitat restoration sites for non-point source pollution management. Ecological Engineering 42.174-182.

[12] Shinde, V. A, Sharma. K.N, Tiwari. M, Singh. 2011. Quantitative determination of soil erosion and prioritization of Micro-Watersheds using RS and GIS. Journal of the Indian society of Remote Sensing 37. 12pp.

[13] Suresh, M. S, Sudhakar. K.N, Tiwari. V.M, Chawdary. 2005. Prioritization of watershed using morphometric parameters and assessment of surface water potential using RS. Journal of the Indian society of Remote Sensing 32.11pp.

[14] Thakkar. A, and S.D, Dhiman. 2007. Morphometric analysis and prioritization of Mini Watershed in MOHR Watershed, Gujaratu sing RS and GIS Techniques. Journal of the Indian society of Remote Sensing 35pp. 